\title{
Growth phase-dependent and differential transcriptional control of flagellar genes in Helicobacter pylori
}

\author{
Eike Niehus, Fang Ye, Sebastian Suerbaum and Christine Josenhans
}

Institute for Hygiene and Microbiology, University of Würzburg, Josef-SchneiderStraße 2, D-97080 Würzburg Germany
Author for correspondence: Christine Josenhans. Tel: +49931 20146905. Fax: +4993120146445. e-mail: cjosenhans@hygiene.uni-wuerzburg.de

\begin{abstract}
Helicobacter pylori possesses two different flagellin genes, flaA and flaB, which are unlinked on the chromosome and transcribed from $\sigma^{28}$ and $\sigma^{54}$ promoters, respectively. Both flagellins are hypothesized to be present in varying amounts in the flagellum, to adapt the physical properties of the flagellar filament to different environmental conditions. The influence of growth phase and environmental conditions on the transcriptional regulation of both flagellin genes has not been investigated so far. Using three different reporter genes as well as Northern blot analyses and RT-PCR, it was determined that both flagellin genes are transcribed in a growth phase-dependent fashion. Growth phase dependency was also found for the flagellar basal body export apparatus gene flhA which is involved in the transcriptional regulation of both flagellin genes. Peak transcription of flaB and flhA occurred earlier during the growth phase than that of flaA, possibly consistent with a hook-proximal localization of the minor flagellin FlaB. Of the reporter gene systems, luciferase fusions reflected best the dynamic regulation patterns of $\boldsymbol{H}$. pylori flagellin genes. Growth phase in vitro had the strongest influence on transcriptional control of $H$. pylori flaA and flaB, while differences in supplements to a rich culture medium had only a modest modulatory effect on flagellin gene transcription.
\end{abstract}

Keywords: gene regulation, transcription, flagellin, reporter genes, flagellar assembly

\section{INTRODUCTION}

The eubacterial genus Helicobacter comprises the gastric Helicobacter species that infect the stomach mucosa of many different kinds of mammals. All of these have developed specific adaptation mechanisms to permit persistent life in the inhospitable environment of the stomach. Helicobacter pylori, the causative agent of chronic gastritis and peptic ulcers in humans, like other Helicobacter species depends on its strong motility to move through the viscous mucus gel lining the epithelium of the human stomach, to establish chronic infection of the human gastric mucosa and to persist in the gastric mucus (Hazell et al., 1986; Worku et al., 1999). The flagella of gastric Helicobacter sp. (H. pylori, $H$. mustelae, $H$. felis) possess complex flagellar filaments composed of two flagellin subunits, FlaA and FlaB.

Abbreviations: CAT, chloramphenicol acetyl transferase; GFP, green fluorescent protein; RLU, relative luminescence unit.
Flagellar filaments contain FlaA and FlaB subunits in a stoichiometric ratio of approximately ten to one (Kostrzynska et al., 1991; Suerbaum et al., 1993; Josenhans et al., 1995a, 1999). Mutants lacking the major flagellin FlaA show strongly impaired motility in vitro and possess only truncated flagella, whereas flaB mutants have moderately diminished motility and apparently normal flagella. In the gnotobiotic piglet animal model and the H. mustelae-ferret model, isogenic mutants lacking either the FlaB or the FlaA subunits were both severely impaired in their ability to colonize (Andrutis et al., 1997; Eaton et al., 1996). Those results demonstrated the importance of both flagellins in vivo. The H. pylori flaA and $f l a B$ genes are unlinked on the chromosome and their transcription is regulated by two different promoters (Leying et al., 1992; Suerbaum et al., 1993). Expression of flaA is controlled by a $\sigma^{28}$ dependent promoter, a class of promoters responsible for the transcriptional activation of late flagellar genes in many flagellated bacteria (class 3; Aizawa, 2000; Josenhans et al., 2002). flaB and several other flagellar 
genes of $H$. pylori are preceded by a $\sigma^{54}$ promoter and have been found to be under the transcriptional control of FlgR, a transcriptional activator of $\sigma^{54}$-dependent genes (Spohn \& Scarlato, 1999, 2001). Dependency of a number of flagellar genes on the 'environmentally regulated' $\sigma^{54}$ factor has also been observed in Caulobacter crescentus, Vibrio cholerae and Campylobacter species, (Anderson et al., 1995; Jagannathan et al., 2001; Prouty et al., 2001). However, the evolutionary, environmental and functional basis for the importance of $\sigma^{54}$ promoters in flagellar regulation in all these bacterial species is not well established.

The genetic background and global regulation of flagellar motility and signal transduction in Helicobacter species have not been thoroughly investigated yet. The complete genome sequences of two $H$. pylori strains have confirmed that both strains possess most motility genes known from other bacteria, but that these are much less frequently organized in operons than in most other bacteria (Alm et al., 1999; Tomb et al., 1997). Based on homology searches, some genes known from other bacteria to be important in motility regulation have not been identified in H. pylori (Josenhans \& Suerbaum, 2001). Notably, H. pylori lacks homologues of genes encoding the flagellar master regulators FlhD and FlhC. The mechanisms of motility regulation in $H$. pylori are thus significantly different from those in other bacteria, most likely due to specific adaptation to their ecological niche. We hypothesized that H. pylori motility, and in particular the expression level of $H$. pylori $\mathrm{FlaB}$, can be regulated in response to specific environmental signals to change the mechanical properties of the flagellar filament.

In the present work, we constructed and characterized reporter gene fusions of the $H$. pylori fla $A$ and flaB promoters and of the flagellar basal body gene $f l h A$ of $H$. pylori in order to study flagellin gene regulation in vitro and in vivo. Fusions with promoterless cat [encoding chloramphenicol acetyl transferase (CAT)], gfp [encoding green fluorescent protein (GFP)] and $\operatorname{lu} x A B$ (encoding luciferase) genes were utilized for this purpose. The $\operatorname{lu} x A B$ operon is described for the first time as a transcriptional reporter in $H$. pylori. Expression and activity levels of the reporter proteins in the H. pylori fusion mutants were determined during the growth phases in liquid culture and under various growth conditions in vitro. We found that transcription of the regulatory gene $f h A$ as well as of both flagellin genes was profoundly influenced by the growth phase but only slightly modulated by the different in vitro growth conditions used. The results support a model of a predominantly growth phase-dependent differential regulation of both $\sigma^{28}$ - and $\sigma^{54}$-controlled $H$. pylori flagellin genes.

\section{METHODS}

Bacterial strains and growth conditions. H. pylori N6 wildtype strain (Cussac et al., 1992) was chosen for the allelic exchange mutagenesis because of its high transformation efficiency. Escherichia coli strains MC1061 and DH5 $\alpha$ were used for the DNA cloning experiments. For the transposon mutagenesis of $H$. pylori flaB in E. coli, we used E. coli strains S17-1[pTCA,pILL638], E. coli lambda cre Rif and E. coli DH1 (Labigne-Roussel et al., 1988).

H. pylori strains were cultured on blood agar plates (Columbia agar base II, Oxoid), supplemented with $10 \%$ sheep blood and the following antibiotics: vancomycin $\left(10 \mathrm{mg} \mathrm{l}^{-1}\right)$, polymyxin B $\left(2500 \mathrm{U} \mathrm{l}^{-1}\right)$, trimethoprim $\left(5 \mathrm{mg} \mathrm{l}^{-1}\right)$ and amphotericin B $\left(4 \mathrm{mg} \mathrm{l}^{-1}\right)$. Plates were incubated for $48 \mathrm{~h}$ at $37^{\circ} \mathrm{C}$ under microaerobic conditions. flaA-cat mutants were propagated on plates with the addition of chloramphenicol $\left(10 \mathrm{mg} \mathrm{l}^{-1}\right)$. For selection of flaB-cat mutants, kanamycin at $100 \mathrm{mg} \mathrm{l}^{-1}$ was added to the plates.

For the CAT assays, H. pylori cells harvested in midexponential phase were inoculated (about $5 \times 10^{8}$ cells per $100 \mathrm{ml}$, corresponding to an initial $\mathrm{OD}_{600}$ of approx. 0.04$0 \cdot 06$ ) into BHI broth supplemented with $10 \%$ fetal calf serum and the above-mentioned antibiotics, but without chloramphenicol or kanamycin. They were incubated in a rotary shaker (110 r.p.m.) under microaerobic conditions for several days. Growth was monitored at each harvest by measuring the $\mathrm{OD}_{600}$ of the cultures. Special care was taken to standardize the conditions of inoculation and growth.

E. coli strains were propagated in Luria broth or on LuriaBertani plates supplemented with antibiotics as required: kanamycin $\left(100 \mathrm{mg} \mathrm{l}^{-1}\right), \quad$ chloramphenicol $\left(20 \mathrm{mg} \mathrm{l}^{-1}\right)$, rifampicin (100 $\left.\mathrm{mg} \mathrm{l}^{-1}\right)$, spectinomycin (100 $\mathrm{mg} \mathrm{l}^{-1}$, or for transposon mutagenesis, $\left.500 \mathrm{mg} \mathrm{l}^{-1}\right)$, ampicillin $\left(100 \mathrm{mg} \mathrm{l}^{-1}\right)$ and tetracycline $\left(10 \mathrm{mg} \mathrm{l}^{-1}\right)$.

DNA methods. DNA purification and cloning procedures were performed as described elsewhere (Sambrook et al., 1989). Large-scale plasmid purifications were performed using Qiagen column purification protocols. DNA fragments were extracted from agarose gels with the QiaEX DNA purification kit (Qiagen). DNA restriction and modification enzymes were obtained from Invitrogen Life Technologies or Roche Biochemicals and were used according to the manufacturers' protocols. Plasmids used in this study are listed in Table 1.

Construction of flaA-, flaB- and flhA-cat fusions in $\mathrm{H}$. pylori

flaA-cat fusion. For construction of flaA-cat reporter gene strains, a plasmid (pSUS24) was used that contains the $H$. pylori flaA gene with a cat cassette inserted into its unique BamHI restriction site (Suerbaum et al., 1993). A chromosomal transcriptional fusion of the flaA promoter with cat was generated by electroporation of $H$. pylori N6 with pSUS24 and selection of chloramphenicol-resistant allelic exchange mutants. Electroporation was performed as described by Ferrero et al. (1992).

flaB-cat fusion. The $\sigma^{54}$ promoter of flaB in vitro allows for a relatively low transcriptional activity in $H$. pylori. Therefore, we used a transposon mutagenesis approach to insert a promoterless cat cassette into flaB. A miniTn3-Km-cat transposon, which contains a kanamycin resistance marker (aphA3 ) with a strong promoter in addition to the promoterless cat cassette, was used to perform a transposon mutagenesis of $\mathrm{flaB}$ (pSUS19), using a protocol described by Labigne-Roussel et al. (1988). E. coli cells containing transposon-mutated plasmids were selected on kanamycin-containing plates and characterized by restriction mapping and PCR. One plasmid, pSUS19::9, had a transposon insertion within the first third of the $H$. pylori flaB gene that created a transcriptional fusion of the flaB promoter and the cat cassette. pSUS19::9 was 
Table 1. Plasmids used in this study

\begin{tabular}{|c|c|c|c|}
\hline Plasmid & Brief description & Resistance* & Source \\
\hline pILL638 & $\begin{array}{l}\text { Donor plasmid of the MiniTn3-Km-cat minitransposon, derived } \\
\text { from MiniTn3-Km (pILL553), containing a promoterless cat gene } \\
\text { and a kanamycin resistance cassette (aphA 3'-III) }\end{array}$ & $\mathrm{km}^{\mathrm{r}}$ & A. Labigne \\
\hline pHL319-2-4 & H. pylori flaA gene & $a p^{r}$ & Leying et al. (1992) \\
\hline pSUS19 & H. pylori flaB gene & $\operatorname{spc}^{\mathrm{r}}$ & Suerbaum et al. (1993) \\
\hline pSUS24 & H. pylori flaA-cat fusion & $\mathrm{ap}^{\mathrm{r}}, \mathrm{cm}^{\mathrm{r}}$ & Josenhans et al. (1995a) \\
\hline pSUS19::9 & H. pylori flaB-cat-Km & $\mathrm{cm}^{\mathrm{r}}, \mathrm{km}^{\mathrm{r}}$ & This study \\
\hline pCM4 & Plasmid containing promoterless cat gene & $a p^{r}$ & $\begin{array}{l}\text { Amersham/Pharmacia } \\
\text { Biotech }\end{array}$ \\
\hline pSUS59 & $\begin{array}{l}\text { H. pylori flhA gene in pILL570 [from pUC derivative pSUS40 } \\
\text { (Schmitz et al., 1997)] }\end{array}$ & $a p^{r}$ & This study \\
\hline pSUS59::1 & H. pylori flhA-cat transposon fusion & $\mathrm{ap}^{\mathrm{r}}, \mathrm{cm}^{\mathrm{r}}, \mathrm{km}^{\mathrm{r}}$ & This study \\
\hline pSUS132 & H. pylori flhA fused to a promoterless cat cassette & $\mathrm{ap}^{\mathrm{r}}, \mathrm{cm}^{\mathrm{r}}$ & This study \\
\hline pSUS78 & H. pylori flaB-gfp transcriptional fusion & $\mathrm{km}^{\mathrm{r}}$ & Josenhans et al. (1998) \\
\hline pSUS128 & H. pylori flaA-gfp transcriptional fusion & $\mathrm{km}^{\mathrm{r}}$ & Josenhans et al. (1998) \\
\hline pSUS1609 & H. pylori flaB-lux $A B$ transcriptional fusion & $\mathrm{km}^{\mathrm{r}}$ & This study \\
\hline pSUS1601 & H. pylori flaA-luxAB transcriptional fusion & $\mathrm{km}^{\mathrm{r}}$ & This study \\
\hline
\end{tabular}

* Resistance to ampicillin $\left(\mathrm{ap}^{\mathrm{r}}\right)$, chloramphenicol $\left(\mathrm{cm}^{\mathrm{r}}\right)$, kanamycin $\left(\mathrm{km}^{\mathrm{r}}\right)$, spectinomycin $\left(\mathrm{spc}^{\mathrm{r}}\right)$.

electroporated into $H$. pylori N6 to generate the transcriptional H. pylori flaB-cat fusion mutant.

flhA-cat fusion. The $H$. pylori flhA-cat fusion was generated by MiniTn3-Km-cat shuttle transposon mutagenesis of plasmid pSUS59, a pILL570 derivative that contains a PCR-amplified part $(1.6 \mathrm{~kb})$ of the $\mathrm{flh} A$ gene. One transposon clone carrying the transposon insertion within the first third of the $f l h A$ coding sequence (pSUS59::1) was isolated from E. coli and introduced by electroporation into $H$. pylori N6. In addition, a plasmid pSUS132, which contained a direct insertion of the promoterless cat cassette into $f h A$ in pSUS59, was also used to generate allelic exchange mutants.

The H. pylori flaA-cat, flaB-cat and flhA-cat mutants were characterized by PCR, Western blotting, transmission electron microscopy and motility testing. In addition, the promoter regions of all mutants were resequenced to exclude selection of promoter mutants during the process of allelic exchange mutagenesis. The mutants were shown to exhibit the same phenotypic characteristics as previously described for $H$. pylorifla $A, f l a B$ and $f l h A$ mutants constructed by the insertion of a kanamycin resistance cassette (Suerbaum et al., 1993; Josenhans et al., 1995a; Schmitz et al., 1997).

CAT assays. The expression of CAT by the H. pylori cat fusion mutants was determined with the Roche CAT-ELISA detection kit. Samples of $5 \mathrm{ml}$ were harvested from H. pylori liquid cultures at different time points, washed once in $0.9 \%$ $\mathrm{NaCl}$ and the bacteria pelleted by centrifugation. The pellets were resuspended in $2 \mathrm{ml}$ of $0.9 \% \mathrm{NaCl}$ and lysed by sonication. Cell debris was separated by centrifugation and discarded. The protein concentration of the supernatant was determined with the bichinchoninic acid (BCA) protein assay. Finally, the samples were diluted to a protein concentration of $0.005 \mu \mathrm{g} \mathrm{l}^{-1}$ (flaA-cat), $0 \cdot 01 \mu \mathrm{g} \mu \mathrm{l}^{-1}$ (flaB-cat) and $0 \cdot 1 \mu \mathrm{g} \mu \mathrm{l}^{-1}$ $(f l h A-c a t)$, respectively. $0 \cdot 01 \mu \mathrm{g}$ protein of the flaA-cat samples per well, $0.07 \mu \mathrm{g}$ protein of the flaB-cat samples per well and 1-5 $\mu \mathrm{g}$ of the flbA-cat samples were used in the Roche microtitre-plate CAT assay which was performed as described by the manufacturer. All assays were performed in triplicate. For quantitative standardization of CAT expression, the Roche purified CAT standard was used.

gfp reporter gene fusions of $\boldsymbol{H}$. pylori flaA and flaB genes. The reporter gene fusions with the red-shifted and enhanced gfp variant gfpmut2 (Cormack et al., 1996) were constructed as described previously (Josenhans et al., 1998). The phenotypes were checked by the same methods as for the cat fusion mutants and were shown to be similar (see above, data not shown).

Determination of GFP fluorescence. Bulk measurement of GFP was performed in a Bio-Rad fluorometer equipped with a filter system for red-shifted GFP (excitation wavelength 490 $\mathrm{nm}$, emission $515 \mathrm{~nm}$, narrow band pass filter). Samples were diluted to the same protein concentration of $0 \cdot 1 \mu \mathrm{g} \mu \mathrm{l}^{-1}$ in PBS and measured as samples of $2 \mathrm{ml}$ for $10 \mathrm{~s}$ to get a stable reading.

Construction of luxAB fusions with the $H$. pylori flaA and flaB promoters. flaA- and $f l a B$-promoter fusions with the $\operatorname{lu} x A B$ operon from Vibrio harveyi were constructed by inverse PCR from the plasmids pSUS81 (flaA) and pSUS128 (flaB) which contain the $f l a-g f p$ fusions together with a kanamycin cassette. Primers HPFlaANotI1/HPFlaBNotI1 and HpgfpNotI2 were used to delete the $g f p$ gene from these constructs by inverse PCR and subsequent religation. The deleted $g f p$ fragment was then replaced with the $\operatorname{lu} x A B$ operon $(V$. harveyi) that had been amplified from MiniTn $5 \operatorname{lu} x A B$ (De Lorenzo et al., 1990; Heuner et al., 1999) using primers containing NotI sites (LuxABNotI1 and LuxABNotI2). The resulting plasmids pSUS1609 and pSUS1601 were used to generate allelic exchange mutants in $H$. pylori by natural transformation. The geno- and phenotypes were determined by the same methods as for the cat and $g f p$ fusion mutants and found to be the same (data not shown).

Measurement of luciferase activity. A Hamamatsu photon counting device (Hamamatsu MTP reader) was used for bulk 
measurements of luciferase activity in microtitre plates. Preparation of the bacterial cultures for measurement was as follows. H. pylori bacteria containing the luciferase gene fusions were grown in liquid medium and harvested at different time points throughout the growth phase. The $\mathrm{OD}_{600}$ was measured at each point and adjusted to $0 \cdot 1$ (approx. $3 \times 10^{7}$ bacteria $\mathrm{ml}^{-1}$ ) for each sample. Then $10 \mu \mathrm{l}$ (approx. $3 \times 10^{5}$ bacteria) bacterial suspension were gently mixed with $30 \mu \mathrm{l}$ reaction buffer $(50 \mathrm{mM}$ sodium phosphate buffer, $\mathrm{pH}=7,50 \mathrm{mM} \beta$-mercaptoethanol, $2 \% \mathrm{w} / \mathrm{v}$ BSA), to which the substrate, n-decyl aldehyde, diluted 1:2000 from the stock solution (Sigma), had been added directly prior to the measurement. Samples were pipetted into a black 96-well microtitre plate and measured in the photon counter using the MTP reader CAA software (Hamamatsu Photonics). Counts were taken 5 and $10 \mathrm{~min}$ after starting the reaction. The counting interval was $2 \mathrm{~s}$. In general, at $10 \mathrm{~min}$ after addition of the substrate, the counts were stable and remained stable for at least another $10 \mathrm{~min}$. All measurements were performed in triplicate on two independent samples and each experiment was performed at least three times on different days. Luciferase activity in the graphs is expressed in relative luminescence units (RLU).

RNA preparation, Northern blotting and RT-PCR. RNA was prepared from $H$. pylori bacteria harvested from liquid cultures in different growth phases using the Qiagen RNeasy kit with slight modifications as described elsewhere (Josenhans et al., 2002). Northern blots were performed on DNase Itreated whole RNA samples, which were separated on denaturing formamide agarose gels. Probes for Northern blots were generated and DIG-labelled as previously described (Josenhans et al., 2002). Semiquantitative RT-PCRs were performed on $2 \mu \mathrm{g}$ DNase I-treated RNA samples from different time points. Reverse transcription was performed using a random hexamer primer mix and Superscript II $^{\mathrm{TM}}$ reverse transcriptase (Invitrogen) at $42{ }^{\circ} \mathrm{C}$ for $1 \mathrm{~h}$. After RNase $\mathrm{H}$ digestion, the cDNA was amplified in different PCR reactions on $2.5 \mu \mathrm{l}$ cDNA sample with primers specific for $f l h A$, flaA and $f l a B$ (primer sequences available on request).

\section{RESULTS AND DISCUSSION}

\section{Construction and evaluation of transcriptional reporter fusions of $\boldsymbol{H}$. pylori flagellar genes}

Systematic studies about temporal gene regulation in $H$. pylori are scarce. Few studies describe environmentally and growth phase-regulated expression of virulencerelated genes in H. pylori (Karita et al., 1996; Spohn et al., 1997; van Vliet et al., 2001; Allan et al., 2001; Delany et al., 2001; Joyce et al., 2001). Reporter genes that have been used so far in Helicobacter are xylE, cat, gfp and lacZ (Josenhans et al., 1995b, 1998; Karita et al., 1996; van Vliet et al., 2001, de Vries et al., 2001). Recently, a lac $Z$ reporter transposon strategy has been devised to identify stress-regulated genes in $H$. pylori (de Vries et al., 2001). There is so far no published experimental evidence that permits a direct comparison of the applicability and performance of different reporter gene systems in Helicobacter species. In the present study, we compared three different reporter systems, cat, gfp and $\operatorname{lu} x A B$, to evaluate the transcriptional activities of the $H$. pylori fla $A$ and flaB flagellin gene promoters, and of the early flagellar basal body gene flhA promoter (previously flbA; Schmitz et al., 1997). The phenotypes of the fusion mutants with all three reporter genes described below were found to be non-polar and similar to the phenotypes of the isogenic fla $A, f l a B$ and flh $A$ mutants that were created previously by allelic exchange with a kanamycin cassette-disrupted copy of the genes (Suerbaum et al., 1993; Josenhans et al., 1995a ; Schmitz et al., 1997; data not shown). The two flagellin genes have a distinct regulation via their $\sigma^{28}$ and $\sigma^{54}$ promoters, and their protein expression levels are known to differ greatly (Kostrzynska et al., 1991; Suerbaum et al., 1993). Initially, fusions of the major flagellin gene flaA, which is transcribed very efficiently by means of its $\sigma^{28}$ promoter, were constructed by inserting a promoterless cat cassette into the flaA coding sequence. The cat cassette was chosen to serve the two purposes of providing i) a selective marker for recombinant $H$. pylori flaA $\Omega$ cat strains and ii) a reporter gene, whose expression under the control of the flaA promoter can be assayed. For the weakly transcribed $f l a B$ and $f l h A$ genes, a shuttle transposon mutagenesis approach was used in addition to a simple insertion mutagenesis (Josenhans et al., 1998). For constructing transposon insertions in $E$. coli, a $\mathrm{km}$-cat $\operatorname{Tn} 3$ derivative, which contains a $\mathrm{km}$ cassette with a strong promoter and an additional promoterless cat-cassette, was utilized, which creates a transcriptional fusion of the cat gene to the gene it is inserted into. Transposon insertions in $f l a B$ and $f l h A$ were integrated into the $H$. pylori chromosome by allelic exchange using the mutagenized suicide plasmids. flaAcat as well as flaB-cat and flhA-cat reporter gene fusions led to detectable chloramphenicol resistance in the respective $H$. pylori mutants.

As a second reporter gene fusion system, mainly for subsequent use in visualization of gene regulation in vivo and in cell culture models, fla $A$ and flaB fusions with a promoterless $g f p$ gene (gfpmut2; Cormack et al., 1996) were generated as previously described (Josenhans et al., 1998). Finally, since the results of the experiments with fla-gfp and fla-cat reporter gene assays were ambiguous in some aspects (see below), we constructed $f l a A$ and $f l a B$ transcriptional fusions with the $\operatorname{lu} x A B$ operon of $V$. harveyi, which has been used as a highly sensitive reporter system in different bacterial species and eukaryotes, and is a good reporter for use in vivo and in infected cultures of eukaryotic cells (Baldwin et al., 1984; Kirchner et al., 1989; Heuner et al., 1999). The sensitivities of both CAT expression as measured by ELISA and luciferase activity measured in a photoncounting device were high. The maximal values of CAT expression driven by the flaA promoter were $10000 \mathrm{pg}$ soluble protein $\mu \mathrm{g}^{-1}$ in comparison to a background in negative controls of $50-100 \mathrm{pg} \mathrm{\mu g}^{-1}$ (Fig. 1a). For luciferase, the maximal activity was approximately 50000-60000 RLU for flaA (per $3 \times 10^{5}$ bacteria) in comparison to \pm 0 units for the background in negative controls, which means that it was possible to detect the luminescence emission of five to ten bacteria (Fig. 1b). A lower sensitivity was found for $g f p$, where highest flaA transcriptional activities were only 60 -fold higher $(3000$ units of fluorescence per $200 \mu \mathrm{g}$ soluble protein) than the 
(a)

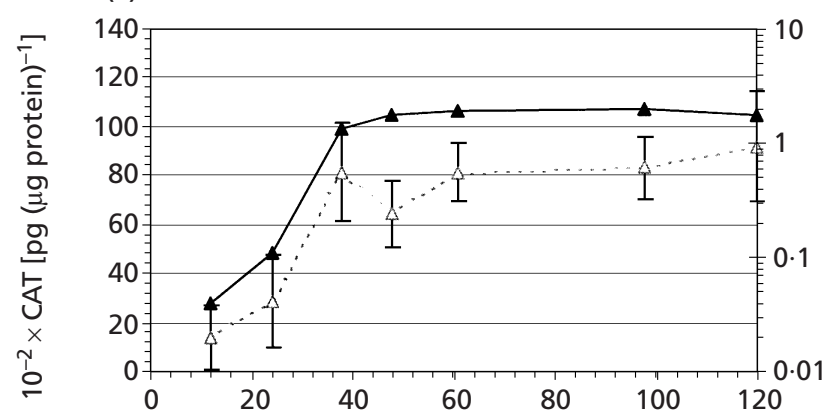

(b)

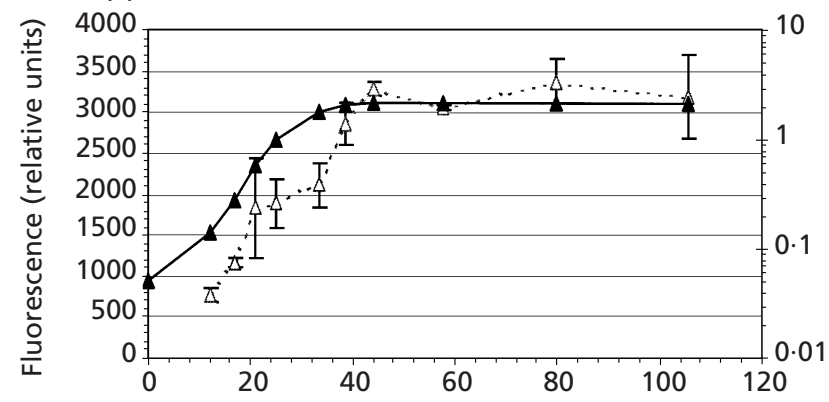

(c)

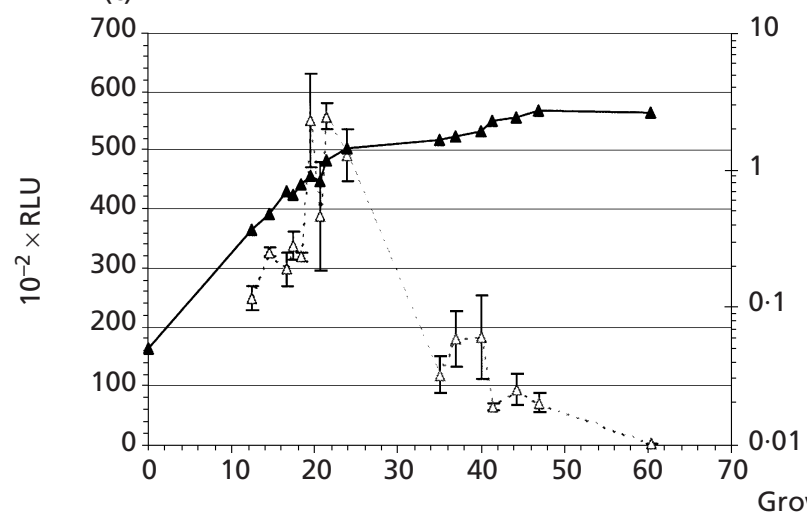

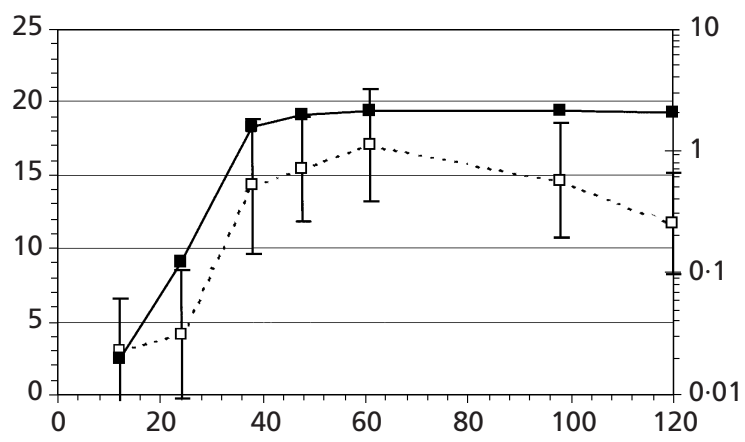
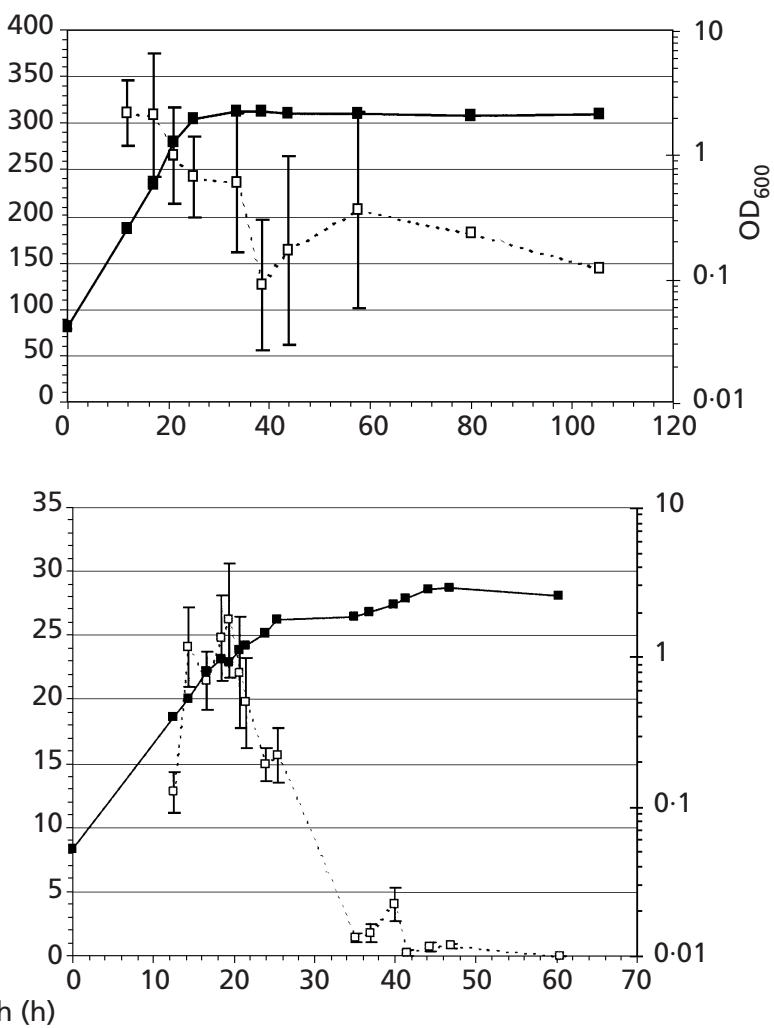

Fig. 1. Growth phase-dependent activity of $H$. pylori fla $A$ and fla $B$ flagellin gene promoters, measured in three different reporter gene systems. Depicted are growth curves (solid lines) and reporter gene measurements (dotted lines) for all three systems used. Solid triangles represent points during the growth curves for flaA, solid squares for flaB. Open triangles depict the reporter measurements for fla $A$, open squares measurements for fla $B$. The growth phases were followed for at least $100 \mathrm{~h}$ (4 days) for the cat and gfp reporters (a, b). For the luxAB reporter genes (c), reporter activities decreased to and stayed near zero after $41 \mathrm{~h}(\mathrm{flaB})$ and $60 \mathrm{~h}(\mathrm{fla} A)$ of growth, therefore the growth curve was stopped at $60 \mathrm{~h}$. All three parts show the mean values and standard deviations from three independently performed experiments. The last two values of the flaA-gfp reporter measurements (b) are the results of one experiment, so no error bars are shown. The left $y$-axes show reporter measurements. Note that the scales of reporter measurements (left $y$ axes) have been chosen differently for fla $A$ and $f l a B$, since the changes between fla $B$ measurements during the growth phases could be assessed more easily. The right $y$-axes show measurement of growth (as $\mathrm{OD}_{600} ;$ an $\mathrm{OD}_{600}$ of 1.0 corresponds to approx. $3 \times 10^{8}$ c.f.u. live bacteria in exponential growth phase) and are drawn to logarithmic scale in each panel. Time of growth (h) is depicted on the $x$-axis. (a) Combined growth curves and determination of CAT expression [pg CAT ( $\mu \mathrm{g}$ protein $)^{-1}$ ] of $H$. pylori flaA- and flaB-cat fusion mutants. Note that expression of the flagellin subunits is regulated roughly in parallel. (b) Growth curves and relative fluorescence measurements of the transcriptional flaA-gfp and flaB-gfp fusion mutants during the growth phases (measured in relative fluorescence units per $\mu \mathrm{g}$ protein). Note the differential transcription of flaA and flaB. (c) Growth curves and luminescence measurements of the transcriptional flaA-luxAB and flaB-luxAB fusions (measured in RLU per $3 \times 10^{5}$ bacteria).

background (50 units per $200 \mu \mathrm{g}$ protein; Fig. 1c). The gfp system was also compromised by high autofluorescence of the H. pylori strains, especially in later phases of growth (Josenhans et al., 1998). In comparison to the systems used in this study, for the $x y l E$ reporter gene, enzymic activities of approximately $1000 \mathrm{mU}(\mathrm{mg}$ 

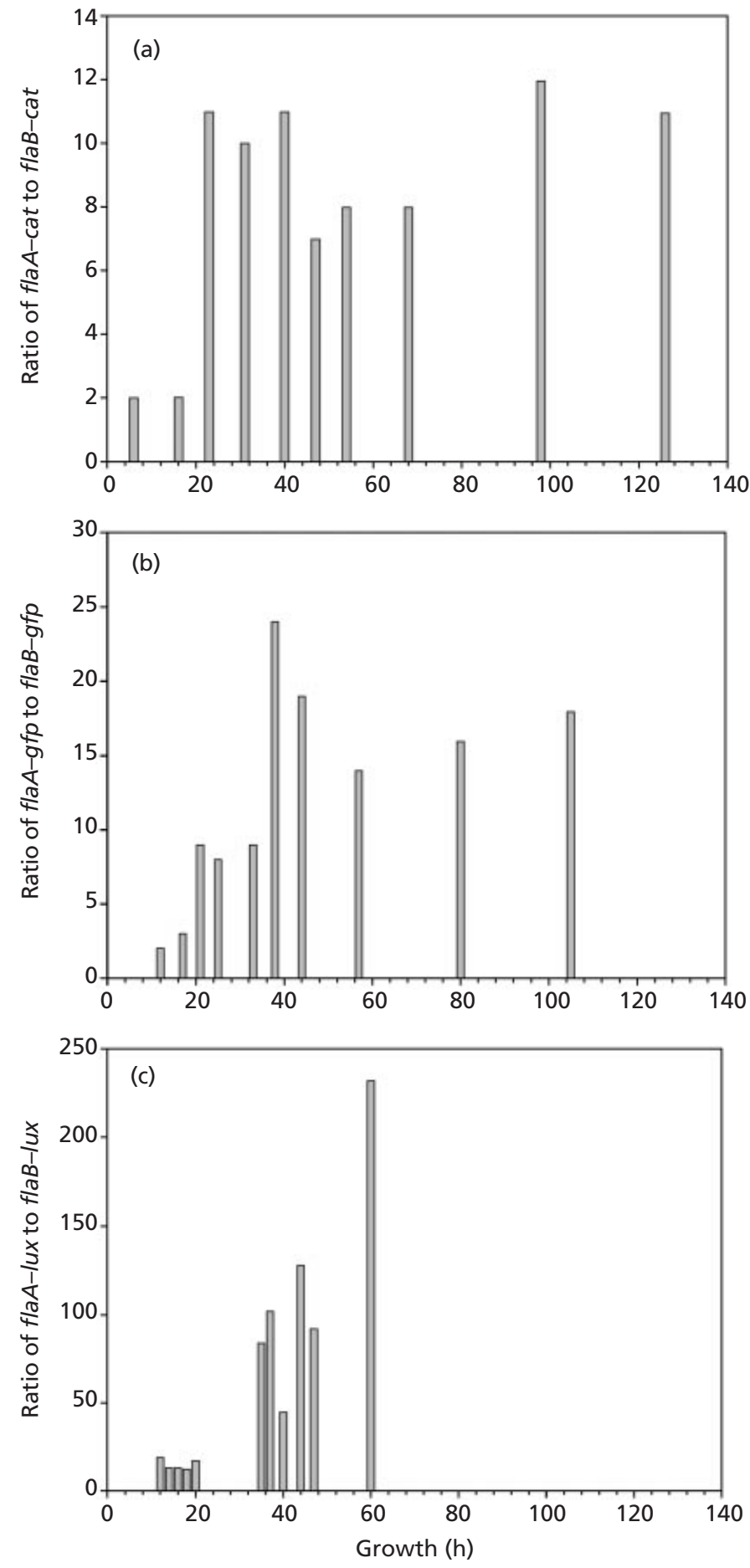

Fig. 2. Ratios of flaA to flaB promoter activities for all three reporter gene systems. Note that the flaA/flaB ratio is lower in the early to mid-exponential phases (up to approx. $20 \mathrm{~h}$ growth, $\mathrm{OD}_{600}$ of about 0.5 ) in all systems and increases from midexponential phase on $\left(O D_{600}\right.$ of approx. 1). Growth curves for the lux reporter fusions were only followed for $60 \mathrm{~h}$ (see Fig. 1). protein $)^{-1}$ were reported in the literature when it was used as a reporter gene for the $H$. pylori vacA and ure $A$ promoters, while the background in negative control measurements was near zero (Karita et al., 1996). Stability of XylE activity was reported to be high. Recently, lacZ was first used as a reporter gene in $H$. pylori, to measure transcriptional activity of the urease operon (van Vliet et al., 2001). However, it has to be noted that even for one of the most active promoters in H. pylori (ureA) this system yielded only very low reporter gene activities, which may be limiting for in vivo gene expression measurements, or for the study of weak promoters.

\section{Growth phase-dependent transcriptional regulation of $H$. pylori flagellar genes flaA, flaB and flhA}

One of our major aims was to determine, if transcription of the flagellar genes in H. pylori is dependent on the growth phases in liquid culture, and if flagellar genes 

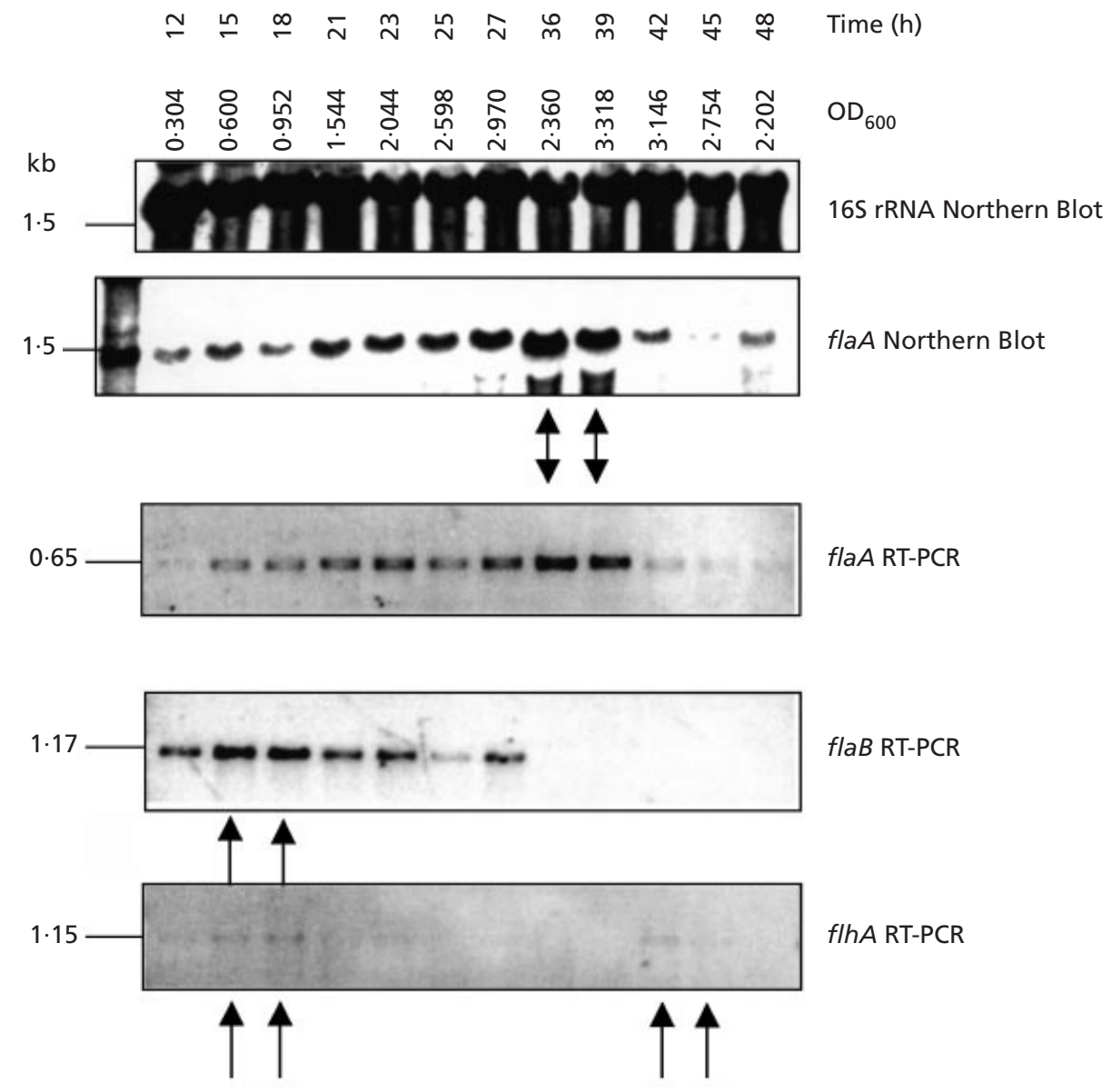

Fig. 3. Northern blots and semiquantitative RT-PCRs of RNA samples prepared from different time points during the growth phases of the $H$. pylori N6 wild-type strain in liquid culture. The results of this experiment are representative for two independently performed experiments. Shown in the upper panels are results for Northern blots with flaA and $16 \mathrm{~S}$ rRNA (control for equal amounts of loaded RNA) probes. Below as indicated, semiquantitative RT-PCRs done from RNA preparations of the same growth curve with primers specific for flaA, flaB and flhA (control of RNA amounts with 16S rRNA-specific primers, not shown). RT-PCRs for flaA, flaB and flhA were allowed to proceed for 20,25 and 33 cycles, respectively.

belonging to different regulons $\left(\sigma^{54}\right.$-dependent, $\sigma^{28}$ dependent) are differentially transcribed during growth in liquid culture in vitro.

In late exponential phase, flaA promoter activity was eight- to 12-fold higher than the activity of the $f l a B$ promoter, as measured by determination of CAT expression of $H$. pylori flaA-cat and flaB-cat mutants and by fluorescence measurement of the GFP reporter protein (Fig. 2). Using the $\operatorname{lu} x A B$ reporter gene fusions, the ratio of $f l a A / f l a B$ reporter activities was even higher in late exponential phase, up to more than 100 -fold.

All three reporter gene systems showed that the expression of both flagellin genes varied strongly in different growth phases (Fig. 1). In addition, in all three systems the ratio of fla $A$ to fla $B$ transcriptional activities varied significantly during the growth phases (Fig. 2), from $3: 1$ (flaA vs $f l a B$ ) at the beginning of the growth phase to more than 10:1 (flaA vs flaB) in later growth phase.
The growth phase-dependent regulation of flagellin genes was reflected slightly differently in the three different reporter gene systems. In the CAT system, where the total amount of CAT protein was measured, reporter activities of both flagellin genes increased exponentially during the mid- to late exponential phases $\left(\mathrm{OD}_{600}\right.$ between approx. 0.5 and 2.0). Reporter levels from both flagellin gene promoters peaked almost in parallel in late exponential phase $\left(\mathrm{OD}_{600}\right.$ of approx. $\left.2 \cdot 0\right)$ and remained at a high level for up to $120 \mathrm{~h}$, probably because of accumulation and high stability of the CAT reporter protein (Fig. 1a). Sometimes a second peak of transcriptional activity was visible after approx. 4 days (96 h) of culture. This growth phase dependency corresponds to findings by Alm and colleagues for Campylobacter coli (Alm et al., 1993), where flaB $\sigma^{54}$ promoter-driven CAT production was maximal in midto late exponential phase.

In the GFP reporter system, where fluorescence of correctly folded, active GFP is measured, the differential 
transcription of both flagellins was most clearly visible. $f l a B$ transcription peaked in early exponential phase, then declined again gradually, whereas flaA transcription peaked only in late exponential phase (Fig. 1b). Luciferase activities (measured as substrate processing; Fig. 1c), of $f l a B$ and $f l a A$ transcriptional fusions peaked closely together in the early to mid-exponential phase, with flaB slightly preceding fla $A$ transcriptional activity. In the luciferase system, both $f l a B$ and flaA transcription rapidly decreased to basal levels in late exponential growth phase, in contrast to the results in the CAT system, where the amounts of reporter proteins appeared to rise almost continuously during the growth cycle, an effect that was likely to be due to the wellknown high stability of the CAT reporter protein.

The results obtained with the three reporter gene systems were compared with Northern blots and semiquantitative RT-PCRs of RNA isolated from the $H$. pylori $\mathrm{N} 6$ wild-type strain. These direct experiments on the mRNA level gave slightly different results, but overall confirmed that significant and differential growth phase-dependent changes occur for flaA and flaB transcription (Fig. 3). Of the three reporter gene systems, only luciferase reflected the transient and dynamic changes visible on the mRNA level at different time points throughout the growth phases, and was the only system that showed a transcriptional downregulation of $f l a A$ at the onset of stationary phase, similar to the Northern blot results. The highest peak of flaA mRNA concentration in the Northern blots and RT-PCRs was in late exponential phase $\left(\mathrm{OD}_{600}\right.$ approx. $\left.2 \cdot 5\right)$, later than the highest reporter gene activity of the flaA-lux fusion. This might indicate that additional mechanisms modulate the outcome of transcriptional regulation in the reporter systems, rather than just a temporal increase in transcription. flaB transcription during the growth phases as measured by semiquantitative RT-PCR and Northern blot (not shown) was significantly different from flaA (Fig. 3). It peaked in early to mid-exponential phase, when flaA transcription was still very low. In contrast, no flaB mRNA was detectable at the later time points during late exponential phase, when flaA transcription was highest. However, for the early time points during growth, transcription of flaA and flaB occurred in parallel.

The flhA promoter activity, which was only measured in the CAT reporter assay and by semiquantitative RTPCR, because of the low activity of the promoter, was also strongly dependent on the growth phase, with a first peak of transcription slightly preceding peak activities of the flaA and flaB promoters in the CAT reporter gene assays (Fig. 4). The FlhA protein is one candidate master regulator in $H$. pylori for growth phase-dependent coordinated transcription of flagellin genes (Schmitz et al., 1997). In a H. pylori flhA mutant, transcription of $f l a A, f l a B$ and $f l g E 1$ (encoding the major hook protein) genes as well as expression of the respective proteins was greatly reduced, dependent on the growth phase (Schmitz et al., 1997). FlhA has been characterized as being one of the early flagellar proteins and part of the

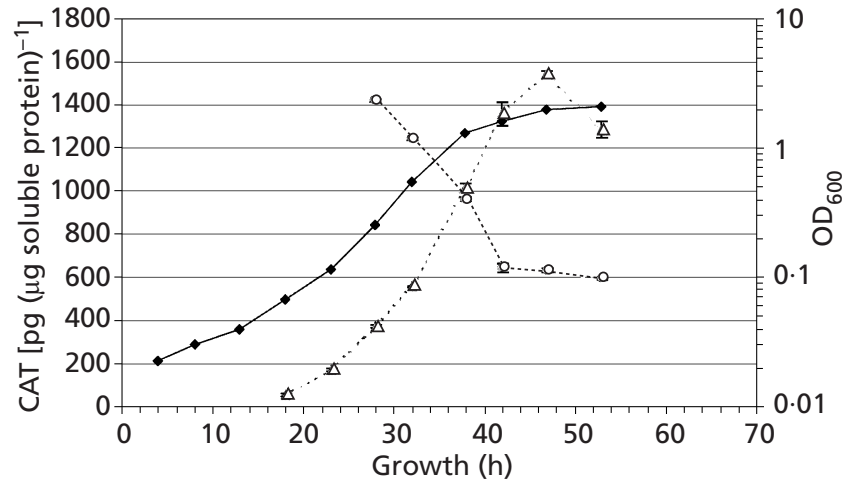

Fig. 4. flhA promoter activity during the growth phases as measured by CAT expression of the flhA-cat reporter gene mutant. For better comparison, flaB-CAT expression is included in the graph. Solid lines/solid squares represent the growth curve. Dotted lines represent the reporter measurements (open triangles: $f l a B$; open circles: flhA). The left $y$-axis shows reporter measurements, the right $y$-axis the $\mathrm{OD}_{600}$ (determination of growth). The $x$-axis shows time of growth (h). The peak of reporter protein expression of the flhA mutant precedes the peak activity in the flaB mutant. flhA promoter activity is significantly lower than that of flaB (one-twentieth), therefore values of flhA measurements were multiplied by 10 to use the same scale on the left $y$-axis.

flagellar basal body export apparatus in Salmonella (Minamino et al., 1994; Minamino \& Macnab, 2000; Kihara et al., 2001). A promoter consensus sequence could not be identified upstream of $f l h A$, except for a TAAA -10 box, similar to those of 'housekeeping' $\sigma^{80}$ promoters of H. pylori (Beier et al., 1998; Vanet et al., 2000). In the present study, the flhA promoter was characterized to be weakly active, with only about onetwentieth of the activity of the $f l a B$ promoter in the cat reporter system (i.e. 200-fold lower transcription levels than the flaA gene). Using semiquantitative RT-PCR of flhA transcription, we could confirm the growth phase dependency of this gene, surprisingly showing a biphasic peak distibution, one in mid-exponential phase (roughly in parallel with flaB transcription), one in the early stationary phase (Fig. 3, bottom panel). However, even with an extended number of polymerization cycles, only very weak signals were obtained. The biphasic distribution of flhA transcriptional activity was also observed in all experiments using the CAT reporter (data not shown).

\section{Influence of environmental factors on regulation of flagellar genes}

The influence of different medium supplements and environmental conditions on the regulation of the two flagellin genes $f l a A$ and $f l a B$ was studied using the cat reporter gene system under the same growth conditions as above (liquid culture in rich, non-defined medium supplemented with serum, see Methods). It would have been preferable to perform such experiments in defined media. However, such media will not support growth of $H$. pylori to high densities and at reproducible growth 
rates, which is why the results concerning the effect of medium supplements have to be interpreted with some caution.

In an evaluation phase, we determined the influence of different medium supplements and incubation temperatures on motility in plate motility assays (Josenhans et al., 1995a). Addition of mucin, which has been reported to be a chemotactic stimulus for H. pylori (Foynes et al., 2000), and of a vitamin (thiamin) to the rich and complex growth medium used in this study did not lead to changes in motility in a soft agar motility assay. Therefore, these parameters were not tested in reporter gene assays. Temperature changes from the optimal H. pylori growth temperature of $37^{\circ} \mathrm{C}$ caused a drastically reduced growth rate of the bacteria, which also led to exclusion of this parameter from further testing.

We evaluated the influence of the following parameters on $f l a A$ and $f l a B$ transcription using the cat reporter: addition of metal ions $\left(1 \mathrm{mM} \mathrm{FeSO}_{4}, 10 \mathrm{mM} \mathrm{MgSO}_{4}\right)$, urea $(8.5 \mathrm{mM}$, approx. two to three times the concentration present in human serum), glutamine $(5 \mathrm{mM})$, different medium viscosities (13 cP, $75 \mathrm{cP}, 1000 \mathrm{cP}$, created by the addition of different percentages of methylcellulose to the medium). Two assays were performed for each condition. Addition of $\mathrm{FeSO}_{4}$ and $\mathrm{MgSO}_{4}$ led to slightly better growth but not to a significant change in flaA-cat or flaB-cat transcription. Increased viscosities or addition of glutamine, a chemoattractant for a number of bacteria, had no significant effect on growth rate or CAT expression. Addition of $8.5 \mathrm{mM}$ urea increased fla $B$ transcription about twofold in all growth phases, while flaA transcription was unaffected. The urea supplement did not alter growth rates of both reporter strains. The medium $\mathrm{pH}$ constantly remained at approximately 7.5 under the conditions used.

Another crucial condition in the lifestyle of H. pylori in the human stomach mucus is likely to be $\mathrm{pH}$. Low $\mathrm{pH}$ values are not easily stabilized in $H$. pylori in vitro culture in the presence of urea, because of medium alkalinization by urea metabolism of the bacterium. Therefore, in our hands, regular H. pylori liquid media such as Brucella or BHI broth supplemented with bovine or horse serum were not useful to maintain a constantly low $\mathrm{pH}$ throughout growth phase regulation experiments. In a special buffered $\mathrm{pH}$-stable culture system (serum-free/urea-free Brucella medium, adjusted to $\mathrm{pH}$ values between 4 and $7 \cdot 5$ in steps of 0.5 , using $15 \mathrm{mM}$ sodium phosphate buffer, and supplemented with $0 \cdot 1 \%$ cyclodextrin), we attempted to measure $\mathrm{pH}$ dependence of flagellin gene expression during the growth phases. The flaA-fusion mutants did not grow well nor reproducibly in this medium. The flaB mutants grew, but only reproducibly at $\mathrm{pH}$ values between 6 and 7.5. There was no difference in flaB-dependent CAT expression within this $\mathrm{pH}$ range. Recently, Allen \& Griffiths (2001) described $\mathrm{pH}$-dependent activities of the Campylobacter jejuni flaA promoter, measured by a luciferase reporter system. In their system, fla $A$ transcriptional activity was moderately higher (about twice) at acidic compared to neutral $\mathrm{pH}$. In a recently published paper dealing with the influence of decreased $\mathrm{pH}(5 \cdot 5)$ on the complete transcriptome of $H$. pylori using macroarrays, flaA was not among the genes under low-pH control, but other flagella-related genes like $f l a B$ showed increased transcriptional activities at an acidic $\mathrm{pH}$ of 5.5 compared to pH $7 \cdot 2$ (Allan et al., 2001). Since $\mathrm{pH}$ changes are clearly one of the key parameters in the natural $H$. pylori ecological niche, further experiments will have to be performed to determine the influence of $\mathrm{pH}$ on flagellin promoter activities in this organism.

\section{Conclusions}

In this work we determined the influence of growth phase and several environmental parameters on the transcriptional regulation of flagellar genes in $H$. pylori by means of reporter gene analyses and direct determination of mRNA levels. This is also the first systematic comparison of three different reporter genes performed for H. pylori, applied to three different gene promoters of very different activities. The advantages and limitations of the three reporter systems, compared to each other, and with methods of direct mRNA detection, were elucidated. The environmental stimuli tested in this work appeared to play a minor role in transcription of $H$. pylori fla $A$ and flaB genes, while leaving growth-phase-related regulation intact. It cannot be excluded that environmental conditions exist in vivo that would lead to more profound changes of differential flagellin gene transcription. Presumably, growth phase regulation by a factor of more than 100 -fold is one important mechanism superimposed over other stimuli as far as regulation of structural flagellar components is concerned. In further studies of H. pylori gene regulation, especially for microarray experiments, great care should be taken to take the influence of growth phase and growth rate into account, since the differences of transcription at different time points were vast.

In Cau.crescentus, E. coli and Salmonella typhimurium, growth phase-dependent or, where synchronization of bacterial cells was possible, growth cycle-dependent flagellar gene expression has been demonstrated. This tightly controlled chain of events has been termed temporal expression of motility-associated genes and is closely linked to other events during the cell cycle (e.g. cell division). Systematic investigations of the temporal regulation of flagellar genes in other bacteria have been done by reporter gene analyses as well as by proteome and transcriptome approaches (Grunenfelder et al., 2001; Kalir et al., 2001; Laub et al., 2000). In H. pylori, flaB showed a transcription peak prior to fla $A$ during the growth curve, possibly consistent with the ultrastructural finding that $\mathrm{FlaB}$ is a hook proximal flagellin subunit (Kostrzynska et al., 1991), which is incorporated into the growing filament before FlaA. Methods to synchronize $H$. pylori cells are not available, and thus a direct measurement of growth cycle influences is not possible. However, we believe that some extrapolations from the growth phases upon growth cycle effects are 
possible, especially at early and late time points. $f h A$, a gene encoding an early (putative class 1) flagellar protein, which is part of the flagellar type III secretion apparatus in the bacterial membrane, showed its transcriptional peak in parallel or slightly prior to $f l a B$ and significantly prior to flaA during the growth phases. Dependence of transcription of late flagellar proteins on FlhA, as has been observed previously (Schmitz et al., 1997), might be one of the mechanisms of temporally regulated flagellar biosynthesis in $H$. pylori. In $V$. cholerae and Cau. crescentus, two bacterial species of the Proteobacteria, which, like H. pylori, express more than one flagellin, but do not possess a flagellar master operon $f h C D$, a large part of the flagellar biosynthesis programme appears to be under the control of $\sigma^{54}$, independently of environmental conditions (Prouty et al., 2001; Grunenfelder et al., 2001). The same seems to be true for $H$. pylori. Bacteria have apparently developed at least two separate pathways during evolution to control the ordered transcription of early and late flagellar genes. One pathway, exemplified by the Salmonella paradigm, is characterized by the superimposed regulation by the master regulators FlhCD, the other is characterized by the dependency of many flagellar genes on $\sigma^{54}$ and further unknown master regulators (one of them probably FlhA), such as in Vibrio, Cau. crescentus, Helicobacter and Campylobacter. Our own preliminary results of comprehensive transcript analyses (E. Niehus, S. Suerbaum and C. Josenhans, unpublished data) indicate that $\sigma^{54}$-dependent genes (such as $f l a B$ and the hook subunit gene $f(g E$ ), in addition to being transcribed prior to $\sigma^{28}$-dependent genes (such as flaA) during the growth phases, are subject to a more sophisticated order of transcription.

In this study, we have laid the groundwork for understanding growth phase-related regulation of flagellar genes in $\mathrm{H}$. pylori, which will continue to be of use to validate candidate genes for regulation studies in vivo. These cornerstones are also a prerequisite for further work on flagellar gene regulation and the global regulatory networks in this fastidious slow-growing bacterium. It would be preferable to directly measure cell cycle-dependent events in H. pylori, using cell cyclesynchronized bacteria, which has not been established so far for any slow-growing bacterium. Further investigations to clarify the temporal regulation and the regulatory network governing Helicobacter motility and flagellar biosynthesis during the growth cycle in vitro and in vivo are presently under way in our laboratory.

\section{ACKNOWLEDGEMENTS}

We are very grateful to Agnès Labigne for the gift of plasmid pILL638 prior to publication. We thank Susanne Friedrich for expert technical assistance and Allison Stack and Joanna Andrzejewska for critical comments on the manuscript. Klaus Heuner is gratefully acknowledged for providing the source of the $\operatorname{lu} x A B$ cassette. The work was supported by grants $\mathrm{Su}$ 133/2-3 and Su 133/2-4 from the Deutsche Forschungsgemeinschaft. F. Y. is a recipient of a PhD student fellowship from the DFG European Graduate College 'Gene Regulation in and by Microbial Pathogens'.

\section{REFERENCES}

Aizawa, S.-I. (2000). Flagella. In Encyclopedia of Microbiology, 2nd edn, pp. 380-389. Edited by J. Lederberg. New York, NY: Academic Press.

Allan, E., Clayton, C. L., McLaren, A., Wallace, D. M. \& Wren, B. W. (2001). Characterization of the low-pH responses of Helicobacter pylori using genomic DNA arrays. Microbiology 147, 2285-2292.

Allen, K. J. \& Griffiths, M. W. (2001). Effect of environmental and chemotactic stimuli on the activity of the Campylobacter jejuni flaA sigma(28) promoter. FEMS Microbiol Lett 205, 43-48.

Alm, R. A., Guerry, P. \& Trust, T. J. (1993). The Campylobacter sigma $54 \mathrm{flaB}$ flagellin promoter is subject to environmental regulation. J Bacteriol 175, 4448-4455.

Alm, R. A., Ling L.-S. L., Moir D. T. \& 20 other authors (1999). Genomic-sequence comparison of two unrelated isolates of the human gastric pathogen Helicobacter pylori. Nature 397, 176-180.

Anderson, D. K., Ohta, N., Wu, J. \& Newton, A. (1995). Regulation of the Caulobacter crescentus rpoN gene and function of the purified sigma 54 in flagellar gene transcription. Mol Gen Genet 246, 697-706.

Andrutis, K. A., Fox, J. G., Schauer, D. B., Marini, R. P., Li, X., Yan, L., Josenhans, C. \& Suerbaum, S. (1997). Infection of the ferret stomach by isogenic flagellar mutant strains of Helicobacter mustelae. Infect Immun 65, 1962-1966.

Baldwin, T. O., Berends, T., Bunch, T. A., Holzman, T. F., Rausch, S. K., Shamansky, L., Treat, M. L. \& Ziegler, M. M. (1984). Cloning of the luciferase structural genes from Vibrio harveyi and expression of bioluminescence in Escherichia coli. Biochemistry 23, 3663-3667.

Beier, D., Spohn, G., Rappuoli, R. \& Scarlato, V. (1998). Functional analysis of the Helicobacter pylori principal sigma subunit of RNA polymerase reveals that the spacer region is important for efficient transcription. Mol Microbiol 30, 121-134.

Cormack, B. P., Valdivia, R. \& Falkow, S. (1996). FACS-optimized mutants of the green fluorescent protein (GFP). Gene 173, 33-38.

Cussac, V., Ferrero, R. L. \& Labigne, A. (1992). Expression of Helicobacter pylori urease genes in Escherichia coli grown under nitrogen-limiting conditions. J Bacteriol 174, 2466-2473.

Delany, I., Spohn, G., Rappuoli, R. \& Scarlato, V. (2001). The Fur repressor controls transcription of iron-activated and -repressed genes in Helicobacter pylori. Mol Microbiol 42, 1297-1309.

De Lorenzo, V., Herrero, M., Jakubzik, U. \& Timmis, K. (1990). Mini-Tn5 transposon derivatives for insertion mutagenesis, promoter probing, and chromosomal insertion of cloned DNA in gram-negative eubacteria. J Bacteriol 172, 6568-6572.

de Vries, N., Kuipers, E. J., Kramer, N. E., van Vliet, A. H., Bijlsma, J. J., Kist, M., Bereswill, S., Vandenbroucke-Grauls, C. M. \& Kusters, J. G. (2001). Identification of environmental stressregulated genes in Helicobacter pylori by a lac $Z$ reporter gene fusion system. Helicobacter 6, 300-309.

Eaton, K. A., Suerbaum, S., Josenhans, C. \& Krakowka, S. (1996). Colonization of gnotobiotic piglets by Helicobacter pylori deficient in two flagellin genes. Infect Immun 64, 2445-2448.

Ferrero, R. L., Cussac, V., Courcoux, P. \& Labigne, A. (1992). Construction of isogenic urease-negative mutants of Helicobacter pylori by allelic exchange. J Bacteriol 174, 4212-4217.

Foynes, S., Dorrell, N., Ward, S. J., Stabler, R. A., McColm, A. A., Rycroft, A. N. \& Wren, B. W. (2000). Helicobacter pylori possesses two CheY response regulators and a histidine kinase sensor, 
CheA, which are essential for chemotaxis and colonization of the gastric mucosa. Infect Immun 68, 2016-2023.

Grunenfelder, B., Rummel, G., Vohradsky, J., Roder, D., Langen, H. \& Jenal, U. (2001). Proteomic analysis of the bacterial cell cycle. Proc Natl Acad Sci US A 98, 4681-4686.

Hazell, S. L., Lee, A., Brady, L. \& Hennessy, W. (1986). Campylobacter pyloridis and gastritis: association with intercellular spaces and adaptation to an environment of mucus as important factors in colonization of the gastric epithelium. J Infect Dis 153, 658-663.

Heuner, K., Brand, B. C. \& Hacker, J. (1999). The expression of the flagellum of Legionella pneumophila is modulated by different environmental factors. FEMS Microbiol Lett 175, 69-77.

Jagannathan, A., Constantinidou, C. \& Penn, C. W. (2001). Roles of $r p o N$, fliA, and flgR in expression of flagella in Campylobacter jejuni. J Bacteriol 183, 2937-2942.

Josenhans, C. \& Suerbaum, S. (2001). Motility and chemotaxis. In: Helicobacter pylori: Molecular and Cellular Biology, pp. 171-184. Edited by M. Achtman \& S. Suerbaum. Wymondham: Horizon Scientific Press.

Josenhans, C., Labigne, A. \& Suerbaum, S. (1995a). Comparative ultrastructural and functional studies of Helicobacter pylori and Helicobacter mustelae flagellin mutants: both flagellin subunits, FlaA and FlaB, are necessary for full motility in Helicobacter species. J Bacteriol 177, 3010-3020.

Josenhans, C., Labigne, A. \& Suerbaum, S. (1995b). Reporter gene analyses show that expression of both H. pylori flagellins is dependent on the growth phase. Gut 37 (Suppl. 1), A62 (abstract).

Josenhans, C., Friedrich, S. \& Suerbaum, S. (1998). Green fluorescent protein as a novel marker and reporter system in Helicobacter sp. FEMS Microbiol Lett 161, 263-273.

Josenhans, C., Ferrero, R. L., Labigne, A. \& Suerbaum, S. (1999). Cloning and allelic exchange mutagenesis of two flagellin genes from Helicobacter felis. Mol Microbiol 33, 350-362.

Josenhans, C., Niehus, E., Amersbach, S., Hörster, A., Betz, C., Drescher, B., Hughes, K. T. \& Suerbaum, S. (2002). Functional characterization of the antagonistic flagellar late regulators FliA and FlgM of Helicobacter pylori and their effects on the H. pylori transcriptome. Mol Microbiol 43, 307-322.

Joyce, E. A., Gilbert, J. V., Eaton, K. A., Plaut, A. \& Wright, A. (2001). Differential gene expression from two transcriptional units in the cag pathogenicity island of Helicobacter pylori. Infect Immun 69, 4202-4209.

Kalir, S., McClure, J., Pabbaraju, K., Southward, C., Ronen, M., Leibler, S., Surette, M. G. \& Alon, U. (2001). Ordering genes in a flagella pathway by analysis of expression kinetics from living bacteria. Science 292, 2080-2083.

Karita, M., Tummuru, M. K., Wirth, H. P. \& Blaser, M. J. (1996). Effect of growth phase and acid shock on Helicobacter pylori cagA expression. Infect Immun 64, 4501-4507.

Kihara, M., Minamino, T., Yamaguchi, S. \& Macnab, R. M. (2001). Intergenic suppression between the flagellar MS ring protein FliF of Salmonella and FlhA, a membrane component of its export apparatus. J Bacteriol 183, 1655-1662.

Kirchner, G., Roberts, J. L., Gustafson, G. D. \& Ingolia, T. D. (1989). Active bacterial luciferase from a fused gene: expression of a Vibrio harveyi lux $A B$ translational fusion in bacteria, yeast and plant cells. Gene 81, 349-354.

Kostrzynska, M., Betts, J. D., Austin, J. W. \& Trust, T. J. (1991). Identification, characterization, and spatial localization of two flagellin species in Helicobacter pylori flagella. J Bacteriol 173, 937-946.

Labigne-Roussel, A., Courcoux, P. \& Tompkins, L. (1988). Gene disruption and replacement as a feasible approach for mutagenesis of Campylobacter jejuni. J Bacteriol 170, 1704-1708.

Laub, M. T., McAdams, H. H., Feldblyum, T., Fraser, C. M. \& Shapiro, L. (2000). Global analysis of the genetic network controlling a bacterial cell cycle. Science 290, 2144-2148.

Leying, H., Suerbaum, S., Geis, G. \& Haas, R. (1992). Cloning and genetic characterization of a Helicobacter pylori flagellin gene. Mol Microbiol 6, 2863-2874.

Minamino, T. \& Macnab, R. M. (2000). Interactions among components of the Salmonella flagellar export apparatus and its substrates. Mol Microbiol 35, 1052-1064.

Minamino, T., lino, T. \& Kutsukake, K. (1994). Molecular characterization of the Salmonella typhimurium flhB operon and its protein products. J Bacteriol 176, 7630-7637.

Prouty, M. G., Correa, N. E. \& Klose, K. E. (2001). The novel sigma54- and sigma28-dependent flagellar gene transcription hierarchy of Vibrio cholerae. Mol Microbiol 39, 1595-1609.

Sambrook, J., Fritsch, E. F. \& Maniatis, T. (1989). Molecular Cloning: a Laboratory Manual, 2nd edn. Cold Spring Harbor, NY : Cold Spring Harbor Laboratory.

Schmitz, A., Josenhans, C. \& Suerbaum, S. (1997). Cloning and characterization of the Helicobacter pylori flbA gene, which codes for a membrane protein involved in coordinated expression of flagellar genes. J Bacteriol 179, 987-997.

Spohn, G. \& Scarlato, V. (1999). Motility of Helicobacter pylori is coordinately regulated by the transcriptional activator FlgR, an NtrC homolog. J Bacteriol 181, 593-599.

Spohn, G. \& Scarlato, V. (2001). Motility, chemotaxis, and flagella. In: Helicobacter pylori. Physiology and Genetics, Chapter 21, pp. 239-248. Edited by H. T. L. Mobley, G. L. Mendz \& S. L. Hazell. Washington: American Society or Microbiology.

Spohn, G., Beier, D., Rappuoli, R. \& Scarlato, V. (1997). Transcriptional analysis of the divergent $\operatorname{cag} A B$ genes encoded by the pathogenicity island of Helicobacter pylori. Mol Microbiol 26, 361-372.

Suerbaum, S., Josenhans, C. \& Labigne, A. (1993). Cloning and genetic characterization of the Helicobacter pylori and Helicobacter mustelae flaB flagellin genes and construction of $H$. pylori flaA- and flaB-negative mutants by electroporation-mediated allelic exchange. J Bacteriol 175, 3278-3288.

Tomb, J.-F., White, O., Kerlavage $\& 39$ other authors (1997). The complete genome sequence of the gastric pathogen Helicobacter pylori. Nature 388, 539-547.

Vanet, A., Marsan, L., Labigne, A. \& Sagot, M. F. (2000). Inferring regulatory elements from a whole genome. An analysis of Helicobacter pylori sigma(80) family of promoter signals. J Mol Biol 297, 335-353.

van Vliet, A. H., Kuipers, E. J., Waidner, B. \& 7 other authors (2001). Nickel-responsive induction of urease expression in Helicobacter pylori is mediated at the transcriptional level. Infect Immun 69, 4891-4897.

Worku, M. L., Sidebotham, R. L., Walker, M. M., Keshavarz, T. \& Karim, Q. N. (1999). The relationship between Helicobacter pylori motility, morphology and phase of growth: implications for gastric colonization and pathology. Microbiology 145, 2803-2811.

Received 1 July 2002; revised and accepted 6 September 2002. 